\title{
Performance Analysis of 200-Gb/s Low Complexity Transmission in Second Window
}

\author{
T.K.Mohanapriya \\ P.G.Student \\ A.C.College of Engineering and \\ Technology \\ Karaikudi, Tamilnadu, India
}

\author{
A.Sivananatharaja \\ Associate Professor \\ A.C.College of Engineering and \\ Technology \\ Karaikudi, Tamilnadu, India
}

\author{
D.Shanmuga Sundar \\ Research Scholar \\ A.C.College of Engineering and \\ Technology \\ Karaikudi, Tamilnadu, India
}

\begin{abstract}
In this paper, a low complexity up to $200-\mathrm{Gb} / \mathrm{s}$ is analyzed over a $38-\mathrm{km}$ standard single mode fiber transmission system in the 1310-nm wavelength domain. The system is based exclusively on semiconductor component without any form of dispersion compensation. The results showed that the 1310$\mathrm{nm}$ wavelength domain can support low cost and low complexity high speed transmission.
\end{abstract}

\section{Keywords}

Optical fiber communication, electro absorption modulator, semiconductor optical amplifier, wavelength division multiplexing.

\section{INTRODUCTION}

An optical communication systems operating at multi-Gbit/s, such as 10 Gigabit Ethernet are becoming increasingly important in local area networks (LANs) and metropolitan area networks (MANs). The second generation $1310 \mathrm{~nm}$ wavelength domain is to realize high capacity, low cost and low complexity transmission. Demonstrated $1310 \mathrm{~nm}$ semiconductor based wavelength division multiplexing (WDM) systems operated at the distance below $100 \mathrm{~km}$, therefore not fully exploiting advantages of the transmission in the $1310 \mathrm{~nm}$ transmission window. An error-free $8 \times 20$ Gbit/s $1310 \mathrm{~nm}$ dense WDM (DWDM) transmission using SOAs over $38 \mathrm{~km}$ of standard single mode fibre without any dispersion compensation. The whole system has simplified, cost-effective design. The current application of $1310 \mathrm{~nm}$ wavelength domain are limited to the upstream channel in fiber to the home systems as well as a newly developed 100G Ethernet standard,[6] where $4 \times 25 \mathrm{~Gb} / \mathrm{s}$ transmission is utilized. Here we present semiconductor based $8 \times 20 \mathrm{~Gb} / \mathrm{s}$ and $8 \times 25$ $\mathrm{Gb} / \mathrm{s}$ DWDM transmission over $38 \mathrm{~km}$ of SSMF in the 1310 $\mathrm{nm}$ wavelength domain[11]. Excellent operation of the system is demonstrated. A high speed and cost effectiveness transmission is achieved in the $1310 \mathrm{~nm}$ wavelength. The SSMF distance is proportional to the dispersion value and also to the square of the bit rate [3]. Therefore operation in the $1310 \mathrm{~nm}$ has an advantage of 10 times distance extension for a given bitrate without any dispersion component.

\section{WORKING PRINCIPLE}

Considering the SSMF fiber, transmission capacity of the $1310 \mathrm{~nm}$ wavelength domain will be limited by the residual chromatic dispersion as well as the four wave mixing effect (FWM).The transmitter consisted of eight continuous wavelength $(\mathrm{CW})$ lasers at wavelengths: $1311.5-1321.2 \mathrm{~nm}$ (IVIII), with the uniform channel spacing equal to $1.4 \mathrm{~nm}$ (250 $\mathrm{GHz}$ ). The channel spacing between DWDM channels is limited by the FWM effect. Uniform adjacent channel spacing was applied. Below the $200 \mathrm{GHz}$ channel spacing the signal is significantly distorted by FWM, for the channel spacing > 250 $\mathrm{GHz}$ the distortions are limited, while not significantly limiting the signal input power.

After passing through the polarization controllers all $\mathrm{CW}$ signals were combined in a following multiplexer. The 250 $\mathrm{GHz}$ channel spacing guaranteed sufficient suppression of the FWM effect. After multiplexer the signals entered an electroabsorption modulator (EAM). In the EAM all signals were modulated simultaneously at the bit rate $25-\mathrm{Gb} / \mathrm{s}$ with a pseudo random bit sequence coming from the pattern generator. To decorrelate the different wavelength channels a $2.5 \mathrm{~km}$ long dispersion shifted fiber (DSF) was used. Semiconductor optical amplifier (SOA) was used to compensate for the losses in the EAM, the DSF and to maximize the transmitter output power. The transmission line was based on the SSMF. After the transmission link, the signals entered a receiver which consisted of an SOA, a demultiplexer and an electro- optical converter.

In the analysis, the 1-dB power penalty dispersion tolerance was set to $60 \mathrm{ps} / \mathrm{nm}$ and $38 \mathrm{ps} / \mathrm{nm}$ for the signals $20 \mathrm{~Gb} / \mathrm{s}$ and $25 \mathrm{~Gb} / \mathrm{s}$, based on the conducted theoretical analysis and simulations. According to the Recommendation G.652 dispersion value limits in the $1310 \mathrm{~nm}$ transmission window. Dispersion values in the $1550 \mathrm{~nm}$ are usually $\approx 17 \mathrm{ps} / \mathrm{nm} \times \mathrm{km}$. In the wavelength range $1306-1319 \mathrm{~nm}$, dispersion value is at least 10 times lower than in the $1550 \mathrm{~nm}$ transmission window. Allowable transmission distance is inversely proportional to dispersion value and inversely proportional to the square of bit rate. At 10-Gbit/s transmission distance is limited to $60 \mathrm{~km}$, at $25 \mathrm{Gbit} / \mathrm{s}$ to $10 \mathrm{~km}$ and at $40 \mathrm{Gbit} / \mathrm{s}$ to 3 $\mathrm{km}$ in the $1550 \mathrm{~nm}$ transmission window. Therefore operation in the 1306-1319 $\mathrm{nm}$ band has an advantage of 10 times distance extension for a given bit rate with respect to the 1550 $\mathrm{nm}$ transmission window without any dispersion compensation. The SSMF has attenuation of $0.3-0.4 \mathrm{~dB} / \mathrm{km}$ around $1310 \mathrm{~nm}$ and $0.2-\mathrm{dB} / \mathrm{km}$ around $1550 \mathrm{~nm}$.

\section{SIMULATION SETUP}

Fig. 1 shows the experimental setup of the low complexity DWDM transmission system in the 1310-nm transmission window. No dispersion compensation was applied. The utilized components were acquired from the commercial suppliers. All CW signals were combined in a multiplexer. After the multiplexer the signals entered an electro-absorption modulator (EAM). The EAM had the $3 \mathrm{~dB}$ RF bandwidth of $39 \mathrm{GHz}$. In the EAM all signals were modulated simultaneously at the bit rate 20 Gigabits/s with the pseudo random bit sequence coming from the pattern generator. 


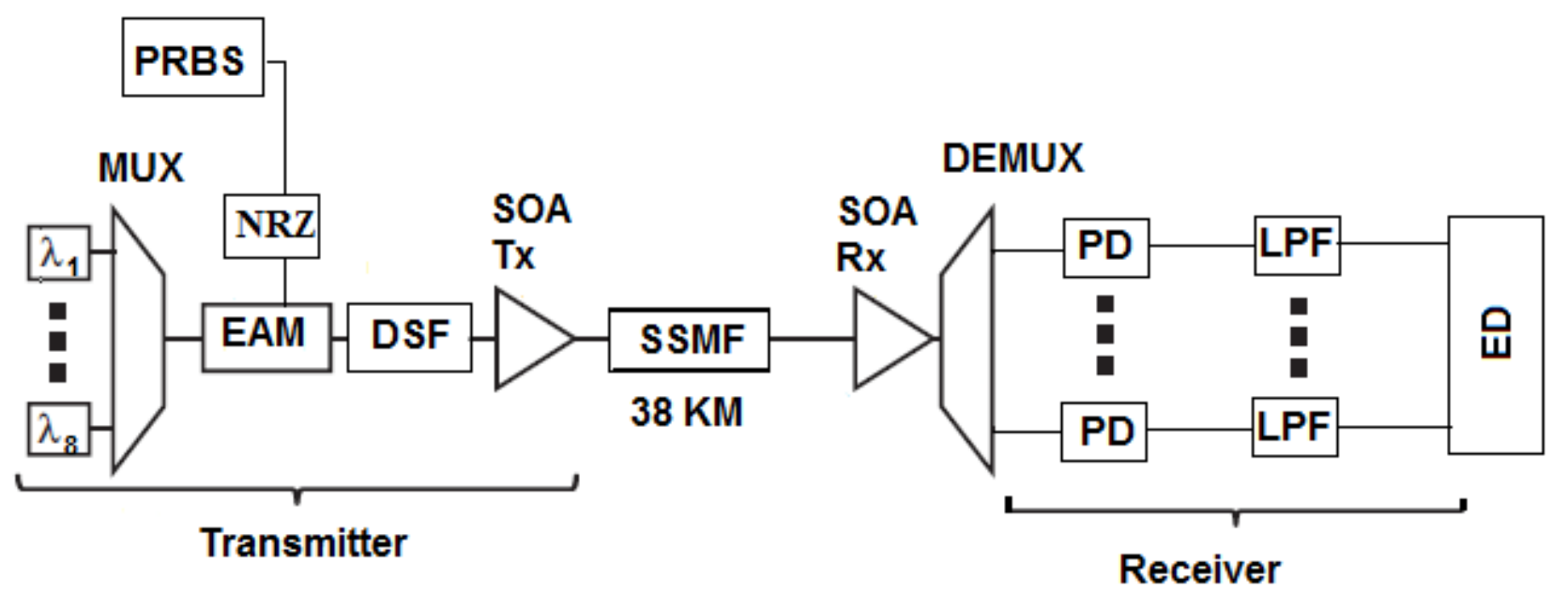

Fig 1: Experimental setup of the low complexity transmission system in the 1310-nm transmission window

To decorrelate the different wavelength channels dispersion shifted fiber (DSF) was used. The DSF had an absolute dispersion value of 42.5- ps/nm and an attenuation of $2 \mathrm{~dB}$. To compensate the losses and to maximize the transmitter output power a semiconductor optical amplifier (SOA) booster was used. The booster SOA had a gain of $10.6 \mathrm{~dB}$ and a nominal saturation power of $13.0 \mathrm{dBm}$. After being simultaneously amplified in the SOA, all signals were injected into the transmission line.

Table 1. Parameters of standard single mode fiber

\begin{tabular}{|c|c|c|}
\hline ATTRIBUTE & DETAIL & VALUE \\
\hline $\begin{array}{l}\text { Dispersion } \\
\text { Coefficient }\end{array}$ & $\mathrm{S}_{0 \max }$ & $0.092 \mathrm{ps} / \mathrm{nm}^{2} \times \mathrm{Km}$ \\
\hline $\begin{array}{l}\text { Attenuation } \\
\text { Coefficient }\end{array}$ & $\begin{array}{c}\text { Maximum at } \\
1310 \mathrm{~nm}\end{array}$ & $0.33-0.35 \mathrm{~dB} / \mathrm{Km}$ \\
\hline $\begin{array}{c}\text { PMD } \\
\text { Coefficient }\end{array}$ & Maximum $\mathrm{PMD}_{\mathrm{Q}}$ & $0.20 \mathrm{ps} / \sqrt{\mathrm{Km}}$ \\
\hline Slope & $\begin{array}{l}\text { At Reference } \\
\text { wavelength }\end{array}$ & $\begin{array}{c}\leq 0.90 \\
\mathrm{ps} /\left(\mathrm{nm}^{2} \times \mathrm{Km}\right)\end{array}$ \\
\hline $\begin{array}{l}\text { Mode Field } \\
\text { Diameter }\end{array}$ & At $1310 \mathrm{~nm}$ & $9.0 \pm 0.4 \mu \mathrm{m}$ \\
\hline
\end{tabular}

The transmission line was based on the SSMF [7] whose properties are listed in Table 1. The parameters of the transmission link were: the length $38.1 \mathrm{~km}$, attenuation at $1310 \mathrm{~nm} 0.325 \mathrm{~dB} / \mathrm{km}$, the zero dispersion wavelength at $1316.3 \mathrm{~nm}$, dispersion at $1310 \mathrm{~nm} 0.281 \mathrm{ps} / \mathrm{nm} * \mathrm{~km}$ and dispersion slope $0.087 \mathrm{ps} / \mathrm{nm} 2 * \mathrm{~km}$. After the transmission link, the signals entered a DWDM receiver. The settings of the electrical signal remained unchanged during all measurements.
Table 2. Simulation Parameters

\begin{tabular}{|l|c|}
\hline Bit rate & $25 \mathrm{Gbps}$ \\
\hline Sequence length & 128 \\
\hline Samples/bit & 64 \\
\hline Channel spacing & $1.4 \mathrm{~nm}$ \\
\hline Capacity & $\begin{array}{c}8-\mathrm{Channels} 25- \\
\mathrm{Gbps}(200-\mathrm{Gbps})\end{array}$ \\
\hline Distance & $10 \mathrm{Km}, 40 \mathrm{Km}$ \\
\hline Input power & $13 \mathrm{dBm}, 20 \mathrm{dBm}$ \\
\hline Effective core area & $65 \mu \mathrm{m}^{2}$ \\
\hline
\end{tabular}

The measured extinction ratio of the modulated $40 \mathrm{~Gb} / \mathrm{s}$ signals was $8.5 \mathrm{~dB}$. To compensate for the losses in the EAM, the DSF and to maximize the transmitter output power a semiconductor optical amplifier (SOA) booster was used. The simulation parameter is listed in Table 2. The DWDM receiver consisted of an SOA, a second AWG and an electrooptical converter. The preamplifying SOA had a gain of 15.7 $\mathrm{dB}$ and a nominal saturation power of $13.0 \mathrm{dBm}$. Next, all signals were fed into a demultiplexing.

\section{SIMULATION RESULT}

Fig. 2 shows the optical spectra after the transmission line. The spectrum resolution of $0.1 \mathrm{~nm}$ was chosen to verify presence of the FWM products. The power level of the signal injected into the transmission line was about $-0.6 \mathrm{dBm}$ per channel. After the transmission line the power level dropped to $-13.2 \mathrm{dBm}$. No four-wave mixing products are visible on the sides of the data channels. The channel power levels are no longer equal after transmission due to the residual polarization and wavelength dependency of the utilized components, as can be observed in the spectrum. 


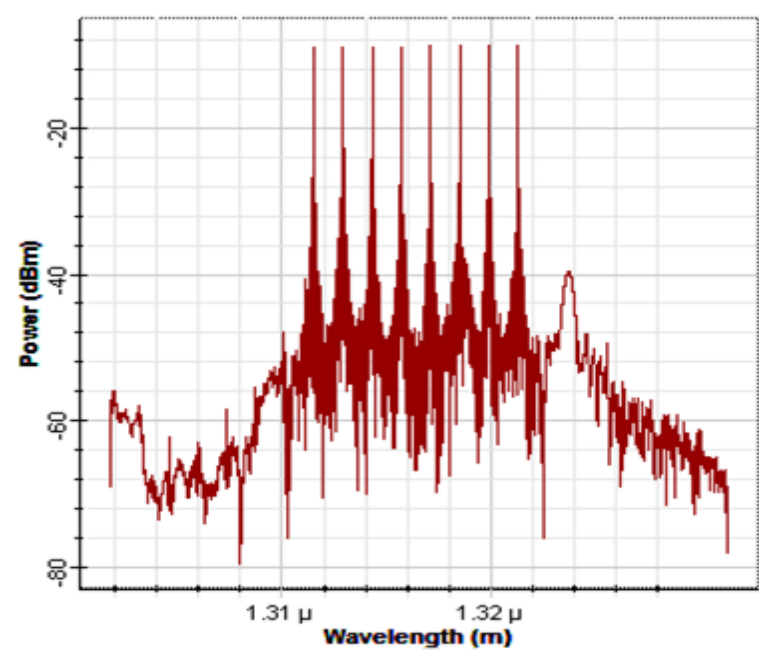

Fig 2: Optical spectra after the transmission line When comparing the signal power levels in the experiments and simulations, note that the simulated signals were ideally copolarized, which increases efficiency of the FWM effect.

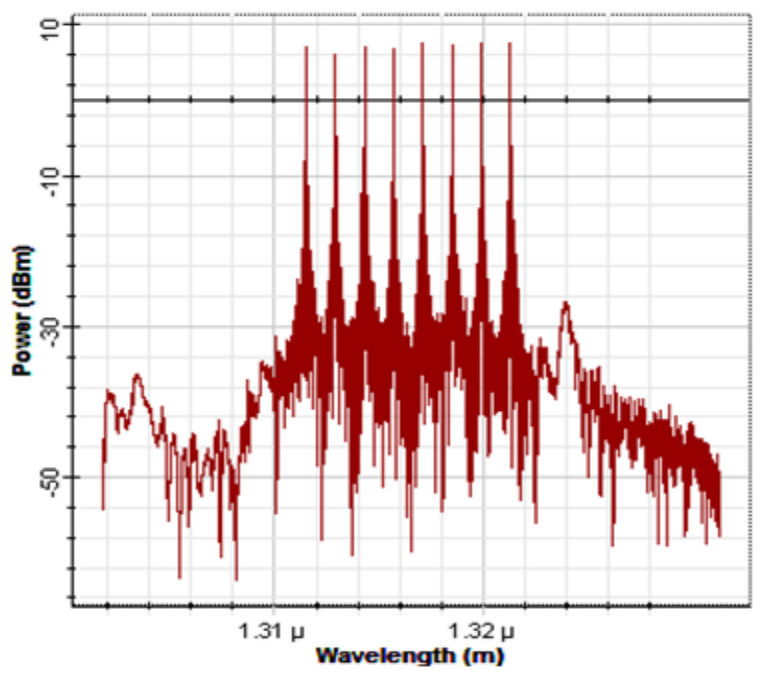

Fig 3: Optical spectra after the preamplifying SOA

Fig. 3 shows the optical spectra after the preamplifying SOA. After the preamplifying SOA the signal reaches a level of 2.2 $\mathrm{dBm}$. The optical signal-to-noise ratio (OSNR) referenced to a $0.1 \mathrm{~nm}$ noise bandwidth dropped from $34.3 \mathrm{~dB}$ after the booster SOA to $31.3 \mathrm{~dB}$ after the pre amplifying SOA. The channel power levels are no longer equal after transmission due to the residual polarization and wavelength dependency of the utilized components, as can be observed in when comparing the signal power levels in the experiments and simulations, note that the simulated signals were ideally copolarized, which increases efficiency of the FWM effect.

Fig. 4 shows the measured eye diagrams for the channel I after the transmitter and before the photodiode. All other channels show a similar performance. All eye diagrams show a clear eye opening and indicate excellent operation of the transmission system. Some signal distortions due to the OSNR degradation and the residual saturation effects are visible in the transmitted signal shows the bit error rate (BER) measurement results. No error floor was observed. The spreading in the system performance is mainly caused by the wavelength and polarization dependence of the utilized components like the multiplexers and the SOAs as well as the fixed conditioning of the EAM driving electrical signal. After changing the PG bit rate to $20 \mathrm{~Gb} / \mathrm{s}$, without any changes in the system setup except the clock signal bypass, an overall system transmission capacity of $160 \mathrm{~Gb} / \mathrm{s}$ was achieved..

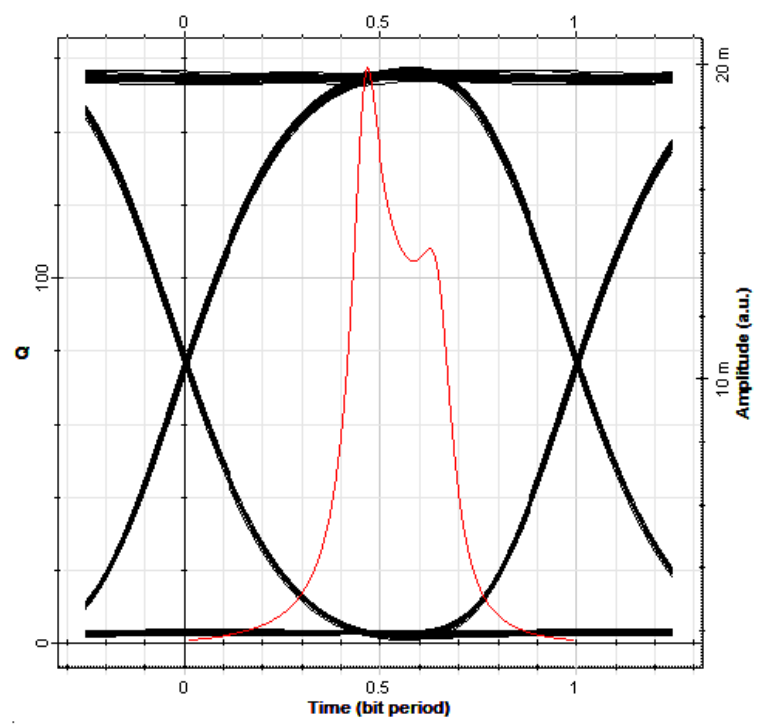

Fig 4: Measured 20-Gb/s eye diagram

Table 3 Simulation Results

\begin{tabular}{|c|c|c|c|}
\hline \multirow{4}{*}{ CHANNELS } & $\begin{array}{c}\text { BIT } \\
\text { RATE } \\
\text { (Gbps) }\end{array}$ & $\begin{array}{c}\text { LENGTH } \\
\text { (Km) }\end{array}$ & Q Factor \\
\hline \multirow{3}{*}{8 Channels } & \multirow{2}{*}{25} & $10 \mathrm{Km}$ & 168.971 \\
\cline { 3 - 4 } & & $20 \mathrm{Km}$ & 137.458 \\
\cline { 3 - 4 } & & $30 \mathrm{Km}$ & 127.894 \\
\cline { 3 - 4 } & \multirow{3}{*}{20} & $40 \mathrm{Km}$ & 124.648 \\
\cline { 3 - 4 } & \multirow{2}{*}{$20 \mathrm{Km}$} & 219.971 \\
\cline { 3 - 4 } & & $20 \mathrm{Km}$ & 176.197 \\
\cline { 3 - 4 } & & $30 \mathrm{Km}$ & 163.937 \\
\cline { 3 - 4 } & & $40 \mathrm{Km}$ & 157.578 \\
\hline
\end{tabular}

Fig.5 shows the measured $25-\mathrm{Gb} / \mathrm{s}$ Eye diagram for the channel I after the transmitter and before the photodiode. All other channels show a similar performance. All eye diagrams show a clear eye opening and indicate excellent operation of the transmission system. Some signal distortions due to the OSNR degradation and the residual saturation effects are visible in the transmitted signal. Figure 5 shows the bit error rate (BER) measurement results. The spreading in the system performance is mainly caused by the wavelength and polarization dependence of the utilized components like the multiplexers and the SOAs as well as the fixed conditioning of the EAM driving electrical signal. 


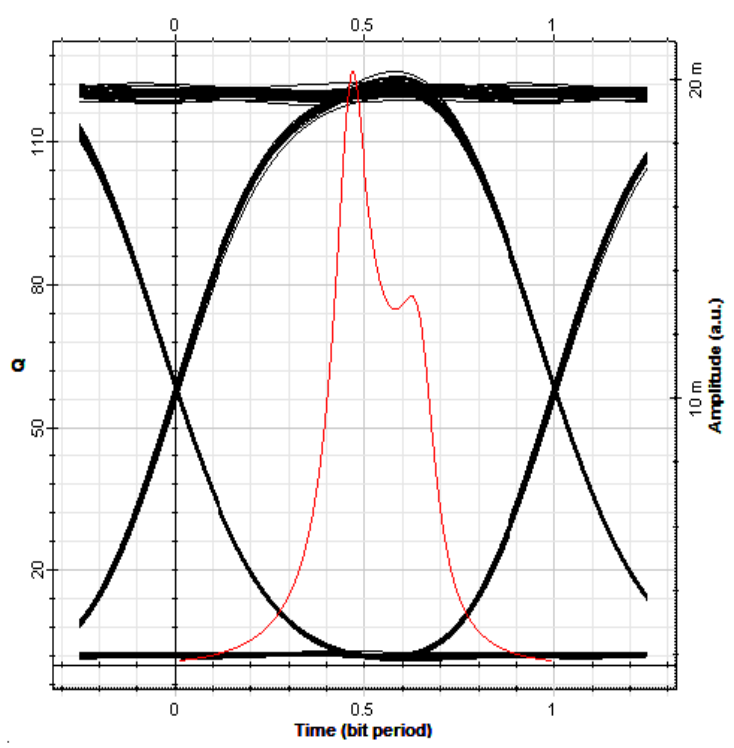

Fig 5: Measured 25-Gb/s eye diagram

After changing the PG bit rate to 25 Gigabit/s, without any changes in the system setup except the clock signal bypass, an overall system transmission capacity of $200-\mathrm{Gb} / \mathrm{s}$ was achieved

\section{CONCLUSION}

The low-complexity transmission system with the capacity up to $160 \mathrm{~Gb} / \mathrm{s}$ in the $1310 \mathrm{~nm}$ wavelength domain, which allowed transmission of $8 \times 20 \mathrm{~Gb} / \mathrm{s}$ over $40 \mathrm{~km}$ of SSMF with the penalty of $0.8 \mathrm{~dB}$ and the average receiver sensitivity of $-15 \mathrm{dBm}$. After increasing the line rate to $25-\mathrm{Gb} / \mathrm{s}$ overall transmission capacity of $200-\mathrm{Gb} / \mathrm{s}$ was achieved with the BER $\leq 2 \mathrm{e}-5$. The presented system has simplified architecture and exclusively semiconductor components are utilized giving prospect for the photonic circuit integration. However, the SOA has in comparison with other optical amplification technologies, not optimal transmission properties, i.e. noise and saturation effects. For low input power signals the SOA output signal is affected by the amplified spontaneous emission (ASE) noise and for high input power signals by pattern effects. The influence of noise and saturation effects was verified in the simple experiment were four $10 \mathrm{Gbit} / \mathrm{s}$ NRZ channels were injected into the SOA and quality of one channel was evaluated in terms of bit error rate (BER) measurements. No dispersion compensation in the optical and electrical domain was applied. The $1310 \mathrm{~nm}$ wavelength domain can be utilized in parallel to the $1550 \mathrm{~nm}$ wavelength domain improving utilization of the legacy fiber infrastructure as well as exclusively, exploring its low-complexity and price advantage. The proposed system can perfectly support the short and medium range future $400 \mathrm{G}+$ Ethernet transmission. Therefore we strongly believe that the $1310 \mathrm{~nm}$ wavelength domain can be utilized significantly expanding its current limited applications

\section{REFERENCES}

[1] IEEE 802.3ba-2010 [Online]. Available: http://standards.ieee.org/getiee802/download/802.3 ba2010.pdf.

[2] T.N.Nielsen, et al., " $8 \times 10 \mathrm{~Gb} / \mathrm{s} 1.3 \mu \mathrm{m}$ unrepeated transmission over a distance of $141 \mathrm{~km}$ with Raman postand pre-amplifiers," IEEE photon. Technol. lett. vol.10, no.10, pp. 1492-1494, Oct.1998.

[3] J.P. Turkiewicz, A.M.J. Koonen, G.D. Khoe, and H. Waardt, "Do we need $1310 \mathrm{~nm}$ transmission in modern networks?" in proc. Opt. commun. Eur. Conf., Cannes, France, 2006, pp. 1-2, paper Te3p.153.

[4] K.Adachi, et al., " $25-\mathrm{Gb} / \mathrm{s}$ multi-channel $1.3 \mu \mathrm{m}$ surfaceemitting lens-integrated DFB laser arrays," J. Lightw. Technol., vol. 29, no.19, pp.2899-2905, Oct. 1, 2011.

[5] T. Fujisawa, et al., " $1.3 \mu \mathrm{m} 4 \times 25-\mathrm{Gb} / \mathrm{s}$, monolithically integrated light source for metro area $100-\mathrm{Gb} / \mathrm{s}$ ethernet,'IEEE photon. Technol. Lett., vol.23, no. 6, pp. 356-358, Mar. 15, 2011.

[6] T.Fujisawa. et al., " $1.3 \mu \mathrm{m}, 50 \mathrm{~Gb} / \mathrm{s}$ electro absorption modulators integrated with DFB laser for beyond 100G parallel LAN applications," Electron. lett., vol. 47, no.12, pp. 708-710. Jun.2011.

[7] ITU-T G.652 Characteristics of a Single-Mode Optical Fiber and Cable.(2009,Nov.). [Online]. Available: http://www.itu.int/rec/T-REC-G.652-200911-I.

[8] Fujisawa, T., Takahata, K., Kobayashi, W., Tadokoro, T., Fujiwara, N., Kanazawa, S., and Kano, F.: '1.3-mm, 50-Gbit/s EADFB lasers for 400GbE'. Proc. OFC'11, Los Angeles, CA, USA, 2011 (OWD4)

[9] E.J.M. Verdurmen et al, Elec. Lett., 41(2005), 349

[10] J.P. Turkiewicz et al, Elec. Lett., 39(2003), 795

[11] G. Lehmann, E. Meissner, S. Spalter, Y.R. Zhou, E. Sikora, and A. Lord "Dispersion tolerances at 160 $\mathrm{Gb} / \mathrm{s}$,"in Proc. Network and Optical Comm. 2002, Darmstadt, Germany, pp. 95-100.

[12] T. Tadokoro, et al., IEEE Photon. Technol. Lett., 21, 16, 1154-1156 (2009).

[13] J.P. Turkiewicz, E. Tangdiongga, H. Rohde, W. Schairer, G.Lehmann, G.D. Khoe, and H.de Waardt, "Simultaneous high-speed OTDM add drop multiplexing using GT-UNI switch," Electron. lett. vol. 39, no.10, pp. 795-796,2003. 